\title{
Evaluation of immune cell markers in tumor tissue treated with radioimmunotherapy in an immunocompetent rat colon carcinoma model
}

Erika Elgström", Sophie E. Eriksson ${ }^{1}$, Otto Ljungberg ${ }^{2}$, Pär-Ola Bendahl ${ }^{1}$, Tomas G. Ohlsson³ ${ }^{3}$ Rune Nilsson ${ }^{1}$ and Jan Tennvall ${ }^{1,4}$

\begin{abstract}
Background: Immune cells within the tumor can act either to promote growth or rejection of tumor cells. The aim of the present study was to evaluate immune cell markers (number and localization) within the tumor before and during rejection due to radioimmunotherapy, to determine whether there is a change in markers related to rejection and/or tolerance of the tumor cells.

Methods: Thirty immunocompetent rats were inoculated with syngeneic rat colon carcinoma cells and 13-14 days later 21 of these rats were treated with $400 \mathrm{MBq} / \mathrm{kg}$ of ${ }^{177}$ Lu-DOTA-BR96 monoclonal antibodies. The treated animals were sacrificed and dissected 1, 2, 3, 4, 6, and 8 days post-injection in groups of three animals per day ( 6 animals on day 8); while the nine untreated animals were sacrificed and dissected on day 0 . Paraffin sections were used for immunohistochemical staining of CD2, CD3, CD8a, CD68, and CD163 antigens. Positive cells were counted within: vital tumor cell areas, necrotic areas, granulation tissue surrounding and between the tumor cell areas. The change in the number of positive cells over time in tumors treated with radioimmunotherapy in the same location was evaluated with linear regression models. The number of positive cells in various locations and the number of various antigen-positive cells within the same location were also evaluated over time using box plots.

Results: There were a higher number of cells expressing immune cell markers in granulation tissue compared with vital tumor cell areas. Cells expressing markers decreased during radioimmunotherapy, and T-cell markers decreased more than macrophage markers in tumors treated with radioimmunotherapy. The expression of CD8a was higher than that of the other T-cell markers evaluated (CD3 and CD2), which could be explained by the additional expression of CD8a by natural killer (NK) cells and a subset of dendritic cells (DCs). The expression of CD68 (all macrophages, DCs, and neutrophils) tended to be higher than that of CD163 (pro-tumor macrophages).
\end{abstract}

Conclusions: In this model, we demonstrated a higher number of positive cells for immune cell markers related to augmenting the immune rejection than immune tolerance of tumor cells in tumors and a decrease in markers during radioimmunotherapy.

Keywords: Radioimmunotherapy; CD2; CD3; CD8; CD68; CD163; Immune cells; Immunocompetent; Tumor microenvironment; Immune rejection

\footnotetext{
* Correspondence: Erika.Elgstrom@med.lu.se

1 Department of Clinical Sciences Lund, Division of Oncology and Pathology,

Lund University, Barngatan 2B, SE-221 85 Lund, Sweden

Full list of author information is available at the end of the article
} 


\section{Background}

Distant metastases are the main reason that patients die from cancer [1]. It is thus important to identify patients with a high risk of developing metastases and try to prevent the development of tumor cells into metastases, since metastases can develop after years of undetectable disease. This has been explained by escape from dormancy using, for example, immunosurveillance [2-6]. This means that tumor cells are present but do not evolve into a detectable tumor due to the action of the immune system. If the immune response fails to suppress the growth of tumor cells, they will evolve into a detectable tumor. It would be informative to evaluate the infiltration of immune cells in the primary tumor [7-11], since it has been shown that immunoscore classification of tumors is a clinically useful prognostic factor $[12,13]$. Immunotherapeutic strategies aiming to overcome the immune tolerance of tumor cells are a new promising approach. An example of this is the use of an immune checkpoint inhibitor (e.g., ipilimumab) directed against the cytotoxic $\mathrm{T}$ lymphocyte antigen (CTLA-4), which has been found to improve the survival of patients with metastatic melanoma [14-16].

Our rat colon carcinoma model is syngeneic, as the cell line used was established in the same rat strain as used in the experiments. The animals are fully immunocompetent making the model more clinically relevant. In a previous study on this immunocompetent syngeneic rat colon carcinoma model, we demonstrated that treatment with ${ }^{177} \mathrm{Lu}$-labeled monoclonal antibodies (radioimmunotherapy, RIT) resulted in local complete response (CR) in the majority of the animals (17 of 19) within 2 weeks [17]. However, half of the animals developed distant metastases during the follow-up period of 100 days postinjection (p.i.).

The therapeutic effect of RIT is derived from both the antibody and the decay of the radionuclide (in this case ${ }^{177} \mathrm{Lu}$ ). To the best of our knowledge, no studies have been carried out to evaluate the effects of RIT on the infiltration of immune cells into tumors. The aim of the present study was, thus, to evaluate immune cell markers (both number and localization) within the local tumor at the time of treatment and during rejection due to RIT, in order to determine whether there is any change in the markers related to rejection and/or tolerance of the tumor cells.

\section{Methods}

The syngeneic animal model

BN7005-H1D2 is a cell line established from a 1,2-dimethylhydrazine-induced colon carcinoma in a Brown Norway (BN) rat [18]. We determined the radiosensitivity of this cell line, expressed as the fraction of survival after 2 Gy to be $0.5\left({ }^{137} \mathrm{Cs}\right.$ radiation source, unpublished data). This is similar to the radiosensitivity of human colorectal carcinoma cell lines [19]. The cells were cultured in RPMI-1640 medium supplemented with $10 \%$ fetal calf serum (both from PAA Laboratories $\mathrm{GmbH}$, Pasching, Austria), $1 \mathrm{mM}$ sodium pyruvate, $10 \mathrm{mM}$ HEPES buffer, and $14 \mathrm{mg} / \mathrm{L}$ gentamicin (all from Gibco, Invitrogen, Carlsbad, CA) at $37{ }^{\circ} \mathrm{C}$, in a humidified environment containing $5 \% \mathrm{CO}_{2}$. The cells were washed in PBS and detached by treatment with trypsin (both from PAA Laboratories $\mathrm{GmbH}$ ).

$\mathrm{BN}$ rats are immunocompetent and express the target antigen (Lewis $\mathrm{Y}, \mathrm{Le}^{\mathrm{y}}$ ) in normal tissues, mainly in the epithelium of the gastrointestinal tract [20], similar to humans [21]. The animals were inoculated with $3 \times 10^{5}$ cells between the peritoneum and the abdominal wall under general anesthesia (isoflurane, Abbott Scandinavia AB, Solna, Sweden). Tumor volumes were calculated as tumor length $\times$ tumor width ${ }^{2} \times 0.4$ [22]. All experiments were conducted in compliance with European legislation on animal welfare and were approved by the Regional Animal Ethics Committee (Malmö/Lunds djurförsöksetiska nämnd). The animals were housed under standard conditions and fed with standard pellets and fresh water ad libitum.

\section{The radioimmunoconjugate}

The chimeric (mouse/human) monoclonal IgG1 antibody BR96 (Seattle Genetics Inc., Seattle, WA) binding to the $\mathrm{Le}^{\mathrm{y}}$ was employed. The tumor-associated antigen $\mathrm{Le}^{\mathrm{y}}$ is expressed on the majority of human epithelial tumors. The dissociation constant between BR96 and the cell line used is $4 \mathrm{nM}$ [23], illustrating its strong binding affinity.

Conjugation of BR96 and DOTA was performed according to Forrer et al. [24]. Briefly, BR96 was transferred to $0.2 \mathrm{M}$ sodium carbonate buffer, $\mathrm{pH} 9.5$, by repeated centrifugation using an Amicon Ultra-15 filter (MW 30 000, Millipore, Billerica, MA). All empty vials were pretreated with $1 \% \mathrm{HNO}_{3}$ and all buffers were pretreated with Chelex-100 (BioRad, Hercules, CA) to remove metals. The DOTA chelate (S-2-(4-isothiocyanatobenzyl)-1, 4, 7, 10-tetraazacyclododecane tetraacetic acid; Macrocyclics, Dallas, TX, $2 \mathrm{mg} / \mathrm{mL}_{2} \mathrm{O}$ ) was added to the BR96 antibody $(100 \mathrm{mg} / \mathrm{mL})$ at a molar ratio of 3:1 (DOTA:BR96) and incubated for $1 \mathrm{~h}$ at $37^{\circ} \mathrm{C}$. The conjugate was purified by repeated centrifugation using an Amicon Ultra-15 filter and transferred to $0.25 \mathrm{M}$ ammonium acetate buffer, $\mathrm{pH} 5.3$, and the final concentration was adjusted to $10 \mathrm{mg} / \mathrm{mL}$ BR96.

MALDI-MS was used to determine the number of DOTA moieties per BR96 molecule, by desalting the sample to $18 \mathrm{M} \Omega \cdot \mathrm{cm} \mathrm{H}_{2} \mathrm{O}$ using a centrifugation filter device, and dividing the increase in molecular mass by 688 (the molecular mass of the DOTA chelate).

The immunoreactivity (i.e. the antigen-binding properties) of DOTA-BR96 relative to BR96 was determined 
from a saturation binding curve, using BN7005 cells as the target antigen. Briefly, increasing concentrations of BR96 and DOTA-BR96 $(40 \mu \mathrm{g} / \mathrm{mL}-40 \mathrm{mg} / \mathrm{mL})$ were added to the cell plate in triplicate and incubated for at least $90 \mathrm{~min}$. The bound BR96/DOTA-BR96 conjugates were detected with rabbit anti-human IgG-HRP (Dako, Glostrup, Denmark), and the equilibrium binding constant $\left(\mathrm{K}_{\mathrm{d}}\right)$ was calculated using Prism 5.02 software (GraphPad Software Inc., binding saturation-one site total, nonspecific binding and background constrained to a constant value of zero). The immunoreactivity was given by the ratio of the binding constants: $K_{d}$ (BR96) $/ K_{d}$ (DOTA-BR96).

Both the DOTA-BR96 conjugate in $0.25 \mathrm{M}$ ammonium acetate buffer and the ${ }^{177} \mathrm{LuCl}_{3}$ solution (MDS Nordion, Vancouver, Canada) were preheated to $45{ }^{\circ} \mathrm{C}$ for $10 \mathrm{~min}$. The DOTA-BR96 solution was then added to the vial containing the radionuclide and incubated at $45^{\circ} \mathrm{C}$ for $15 \mathrm{~min}$. The reaction was quenched with excess DTPA (diethylene triamine pentaacetic acid) for $5 \mathrm{~min}$. The radiolabeled immunoconjugate was diluted in $1 \%$ human serum albumin (HSA, Baxter Medical AB, Kista, Sweden) to prevent radiolysis from affecting the immunoreactivity. The radiochemical purity was determined with instant thinlayer chromatography (ITLC) using a $1 \times 9 \mathrm{~cm}$ silica-gelimpregnated fiberglass sheet as the solid phase and $0.1 \mathrm{M}$ EDTA as the mobile phase. To analyze the radiochemical purity and to detect signs of aggregation or fragmentation, separation was performed using size-exclusion chromatography and high-performance liquid chromatography (HPLC) (using a $7.8 \times 300 \mathrm{~mm}$ molecular sieving column, Phenomenex SEC S3000; Phenomenex, Torrance, CA, eluted with $0.05 \mathrm{M}$ sodium phosphate at $1.0 \mathrm{~mL} / \mathrm{min}$ ).

\section{Radioimmunotherapy with ${ }^{177}$ Lu-DOTA-BR96}

Thirty male BN rats (Harlan, Horst, the Netherlands) were included in the study. Their median weight on the day of administration of RIT (day 0) was $238 \mathrm{~g}$. Twenty-one rats were treated with $400 \mathrm{MBq} / \mathrm{kg}$ body weight of ${ }^{177} \mathrm{Lu}-$ DOTA-BR96 (150 $\mu$ g DOTA-BR96 in 0.4-mL saline with $1 \%$ HSA) by intravenous injection in the tail vein 1314 days after cell inoculation. Our previous study showed that $400 \mathrm{MBq} / \mathrm{kg}$ body weight resulted in CR in 17 of 19 animals [17], and that the maximum tolerable activity was $600 \mathrm{MBq} / \mathrm{kg}$ body weight [25]. The nine remaining animals were left untreated as a control group. The treated animals were sacrificed and dissected $1,2,3,4,6$, and 8 days p.i. in groups of three animals per day ( 6 animals on day 8), while the untreated animals were sacrificed and dissected on day 0 . The tumors were cut in half, fixed in $4 \%$ paraformaldehyde, and embedded in paraffin.

\section{Immunohistochemistry}

Consecutive $4 \mu \mathrm{m}$ paraffin sections were used to detect CD2, CD3, CD8 $\alpha, C D 68$, and CD163. The characteristics of the antibodies and antigens stained are presented in Table 1. Note that all macrophages express CD68, while CD163 is only expressed by M2 (pro-tumor macrophages) [26, 27].

Sections were rehydrated and antigen retrieval was performed using the PT Link pre-treatment (Dako) with Target Retrieval Solution, pH 6 (Dako), preheated to $65^{\circ} \mathrm{C}$. The sections were then heated to $99{ }^{\circ} \mathrm{C}$ for $20 \mathrm{~min}$ and allowed to cool at room temperature for at least $1 \mathrm{~h}$. The slides were rinsed with distilled water, and endogenous peroxidase was blocked by Peroxidase-Blocking Solution, endogenous biotin by Biotin Blocking System, and proteins by Protein Block Serum-Free (all from Dako). The sections were incubated for 1 (CD2 and CD163) or $1.5 \mathrm{~h}$ (CD3, CD8 $\alpha$, and CD68) at room temperature with primary antibody. After washing with Wash Buffer (Dako), the primary antibodies were detected with LSAB2 SystemHRP for use on rat specimens (Dako) according to the manufacturer's instructions. Finally, Liquid DAB+ Substrate Chromogen System (Dako) was used to visualize the antigens before counterstaining with hematoxylin and mounting with Pertex (Histolab, Goteborg, Sweden).

\section{Evaluation of immunohistochemistry sections}

All sections were evaluated blindly by an experienced clinical pathologist $(\mathrm{OL})$. Positive cells were counted in: vital tumor cell areas, necrotic areas, granulation tissue surrounding the tumor cell areas, and between tumor cell areas. The number of positive cells within the highpower field of view of $40 \times\left(0.24 \mathrm{~mm}^{2}\right)$ was evaluated in two hot spots selected to contain evenly distributed positive cells within the field of view. In views with more than 100 positive cells, the number of positive cells along a diameter of the view was counted. The diameter was chosen randomly. The total number $(n)$ of positive

Table 1 Antibody characteristics and antigen expression

\begin{tabular}{llll}
\hline Antigen & Clone (supplier) & Dilution & Antigen expression on tumor-infiltrating cells \\
\hline CD2 & OX-35 (AbD Serotec) & $1: 800$ & T-cells, B-cells, NK cells \\
CD3 & Polyclonal (18-0102, Invitrogen) & $1: 200$ & T-cells \\
CD8a & OX-8 (AbD Serotec) & $1: 200$ & Cytotoxic T-cell, NK cells, DC subset \\
CD68 & ED-1 (AbD Serotec) & $1: 200$ & All macrophages, neutrophils, DC, myeloid progenitors (e.g. myeloid-derived suppressor cell) \\
CD163 & ED-2 (LSBio, LifeSpan BioSciences) & $1: 200$ & Pro-tumor macrophages (M2) [26, 27] \\
\hline
\end{tabular}


cells within the field of view was then calculated using the following equation:

$$
n=\left(\frac{\text { number of positive cells on the diameter }}{2}\right)^{2} \times \pi
$$

The calculated number of positive cells was confirmed by manual counting in three fields of view, and the calculated value correlated very well with the manually counted values (data not shown).

In some cases, the areas were located in a band-like distribution (mainly granulation tissue) and the areas were not always large enough to cover the whole microscopic field of view. In such instances, the field was oriented in such a way that the area was adjusted to include the diameter of the field of view. The number of positive cells was counted along the diameter and the total number of positive cells was calculated as described above. This procedure was considered necessary to be able to compare density of positive cells over time, between different locations and different immune cell markers.

\section{Statistics}

The change in the number of antigen-positive cells was evaluated using simple linear regression of the log count over time. All immune cell markers (CD2, CD3, CD $8 \alpha$, $\mathrm{CD} 68$, and $\mathrm{CD} 163)$ were individually evaluated in the following locations: vital tumor cell areas, granulation tissue surrounding the tumor cell areas and between tumor cell areas. Multiple linear regression models, including tumor volume on day 0 or tumor volume on the day of sacrifice, were used to evaluate the extent to which the time trends were confounded by tumor volume. Although the linear regression models for the different markers and locations did not always show a good fit to the observed data, they still provided an estimate of trends over time. However, the corresponding regression coefficients should be interpreted as average effects over the follow-up period.

Box plots of ratios of different locations (granulation tissue surrounding the tumor cell areas and between tumor cell areas vs vital tumor cell areas), stratified by time interval, were used to visually compare the number of antigen-positive cells for each antigen. The same technique was use to compare the number of positive cells of different antigens within the same location. Null hypotheses of no difference (ratio 1.0) were evaluated separately for each time interval using the Wilcoxon matched-pairs signed rank sum test.

Animals with no tumor (CR) at the time of sacrifice on days 4 and 6 were not included in the analyses. The scar tissue from tumors on day 8 was collected but could not be included in the calculations since they lacked tumor cell areas.

All statistical calculations were performed using Stata 13.1 (StataCorp LP, College Station, TX).

\section{Results \\ The radioimmunoconjugate}

The average number of DOTA molecules conjugated per BR96 antibody was 2.4. The immunoreactivity was 0.9 , indicating that the antigen-binding properties did not change as a result of conjugation with DOTA. The radiochemical purity of ${ }^{177}$ Lu-DOTA-BR96 was analyzed using ITLC and found to be $97 \%$, and less than $1 \%$ of the activity was found in aggregates according to HPLC.

\section{Tumor sampling}

All 30 rats developed local tumors between the peritoneum and the abdominal wall before the day of treatment (day 0 ). The median tumor volume on day 0 was $1140 \mathrm{~mm}^{3}$ (interquartile range $900-1580 \mathrm{~mm}^{3}$ ). The nine untreated control animals were sacrificed, and the tumors were excised on day 0 . The animals treated with RIT were sacrificed and the local tumor was excised 1, 2, 3, 4, 6, or 8 days p.i. in groups of 3 rats per day, apart from day 8 p.i. when 6 rats were sacrificed. Tumor tissues could not be sampled in 5 rats due to CR: on day 4 (1 CR), day 6 (1 $\mathrm{CR}$ ), and day 8 (3 CR) p.i. Scar tissue from tumors was collected from rats showing $\mathrm{CR}$ on day 8 p.i.

\section{T-cell markers-CD2, CD3, and CD8a}

All T-cell markers decreased in tumors treated with RIT compared with untreated tumors in all areas evaluated, although this was not statistically significant in all cases, see Table 2 and Fig. 1. The potential confounding effect of tumor volume (day 0 or at sacrifice) was evaluated using multiple linear regression, and the estimated time trends were essentially the same as without adjustment for tumor volume (data not shown). The T-cell markers were not expressed in necrotic areas, thus necrotic areas were not included in the following analysis.

All T-cell markers had more positive cells in the granulation tissue (both surrounding and between tumor cell areas) than in the vital tumor cell areas (Fig. 2a-c and Table 2). There were a higher number of positive cells for $\mathrm{CD} 8 \alpha$ than $\mathrm{CD} 2$ and $\mathrm{CD} 3$ and a tendency towards more positive cells for CD2 than CD3 both in untreated tumors and treated tumors.

\section{Macrophage markers-CD68 and CD163}

The number of positive cells for both macrophage markers decreased less than T-cell markers in tumors treated with RIT, compared with untreated tumors in all the areas evaluated, see Table 2 and Fig. 3. The potential confounding effect of tumor volume (day 0 or at sacrifice) 
Table 2 Statistical evaluation of the change in immune cell marker positive cells after administration of RIT. The number of antigenpositive cells at day 0 and the average change in positive cells within tumors treated with RIT (\% per day, confidence interval and p value) at different localizations

\begin{tabular}{|c|c|c|c|c|}
\hline Antigen & Localization & $\begin{array}{l}\text { Positive cells on day } 0 \\
\text { median (range) }\end{array}$ & $\begin{array}{l}\text { Average change after admin. } \\
\text { of radioimmunoconjugate } \\
\text { (95\% confidence interval) }\end{array}$ & $p$ value \\
\hline \multirow[t]{3}{*}{$\mathrm{CD} 2$} & Tumor cell areas & $20(0-80)$ & $-30 \%$ per day $(-48$ to -5.5$)$ & 0.022 \\
\hline & Granulation tissue between tumor cell areas & $240(110-450)$ & $-33 \%$ per day ( -51 to -8.2$)$ & 0.015 \\
\hline & Granulation tissue surrounding tumor cell areas & $370(110-370)$ & $-36 \%$ per day $(-52$ to -15$)$ & 0.003 \\
\hline \multirow[t]{3}{*}{ CD3 } & Tumor cell areas & $50(0-150)$ & $-36 \%$ per day $(-49$ to -18$)$ & 0.001 \\
\hline & Granulation tissue between tumor cell areas & $350(150-570)$ & $-24 \%$ per day $(-30$ to +17$)$ & $<0.001$ \\
\hline & Granulation tissue surrounding tumor cell areas & $480(130-910)$ & $-29 \%$ per day $(-36$ to -20$)$ & $<0.001$ \\
\hline \multirow[t]{3}{*}{ CD8a } & Tumor cell areas & $90(30-180)$ & $-10 \%$ per day $(-29$ to +13$)$ & 0.35 \\
\hline & Granulation tissue between tumor cell areas & $260(80-490)$ & $-0.1 \%$ per day $(-4.4$ to +4.9$)$ & 0.95 \\
\hline & Granulation tissue surrounding tumor cell areas & $340(180-530)$ & $-4.7 \%$ per day $(-8.8$ to +0.41$)$ & 0.033 \\
\hline \multirow[t]{3}{*}{ CD68 } & Tumor cell areas & $310(130-640)$ & -1.3 per day $(-11$ to +9.7$)$ & 0.80 \\
\hline & Granulation tissue between tumor cell areas & $510(310-710)$ & $+1.1 \%$ per day $(-2.8$ to +5.3$)$ & 0.56 \\
\hline & Granulation tissue surrounding tumor cell areas & $560(200-910)$ & $-9.7 \%$ per day $(-14$ to -5.1$)$ & $<0.001$ \\
\hline \multirow[t]{3}{*}{ CD163 } & Tumor cell areas & $160(60-380)$ & $-13 \%$ per day $(-26$ to +0.47$)$ & 0.057 \\
\hline & Granulation tissue between tumor cell areas & $190(110-310)$ & $+1.1 \%$ per day $(-2.8$ to +5.3$)$ & 0.56 \\
\hline & Granulation tissue surrounding tumor cell areas & $200(100-380)$ & $-4.2 \%$ per day $(-9.7$ to +1.5$)$ & 0.14 \\
\hline
\end{tabular}

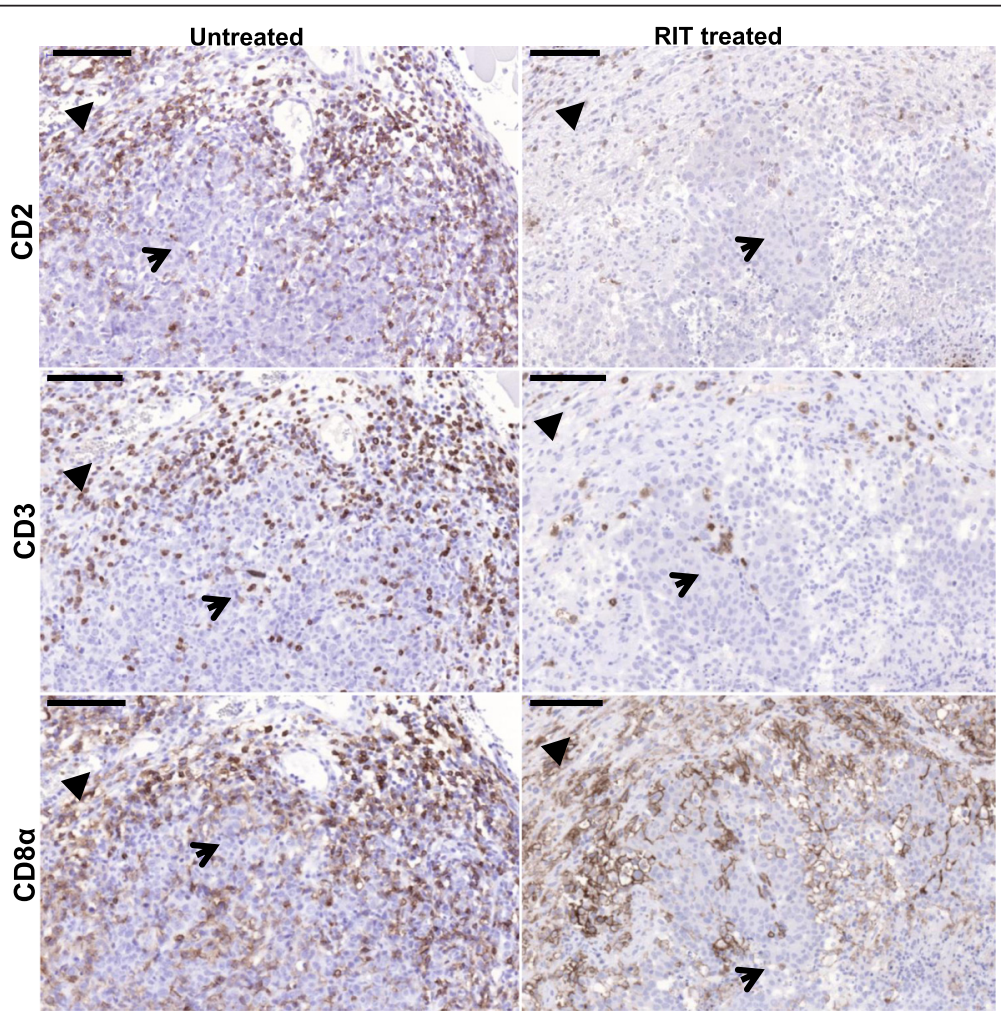

Fig. 1 Images of immunohistochemical sections after staining of T-cell markers. CD2 (T-cells, B-cells, NK cells), CD3 (T-cells), CD8a (cytotoxic T-cells, NK cells, DC subset) in sequential sections of paraffin-embedded tumors. The brown staining illustrates the immune cell markers and the blue staining illustrates the cell nuclei. All images show both granulation tissue (filled arrowhead) and tumor cell area (arrowhead). left: untreated tumors, right: tumor 3 days after administration of radioimmunoconjugate. Note that the decrease of CD8a-positive cells during this interval is less than that of CD2 and CD3. Scale bars: $100 \mu \mathrm{m}$ 


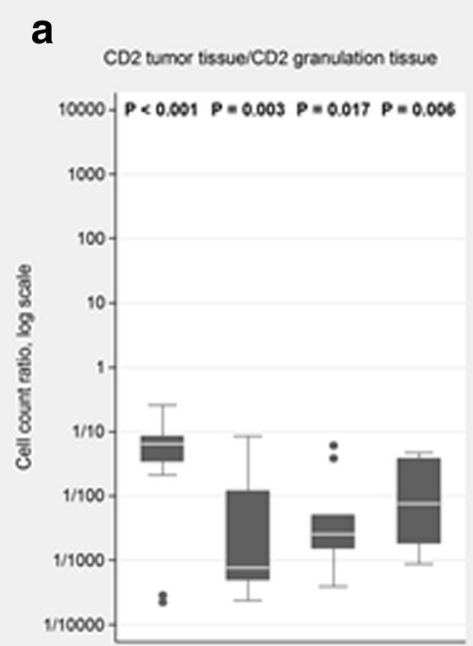

b

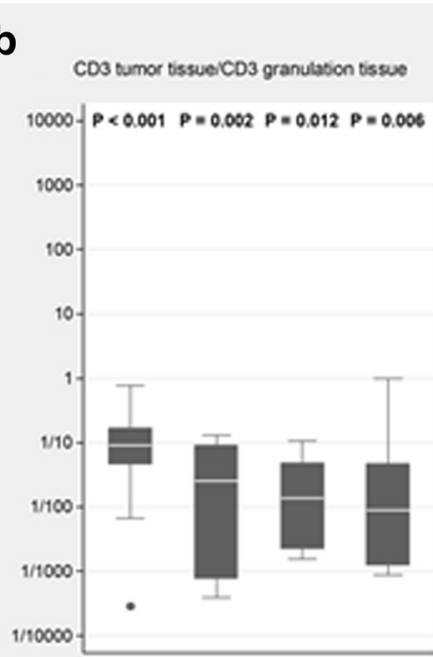

d

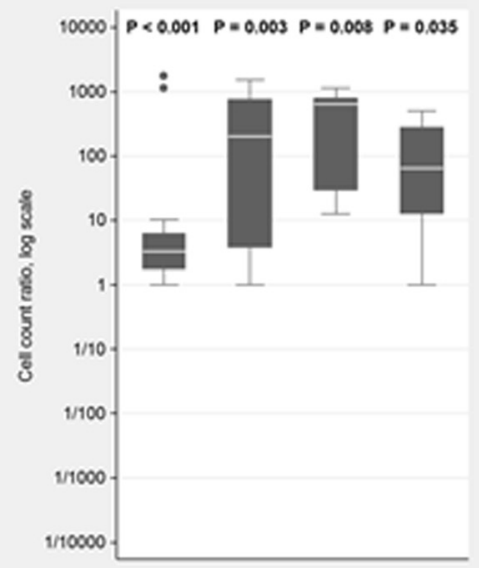

g

CD68 umor tissue/CO68 granulation tissue

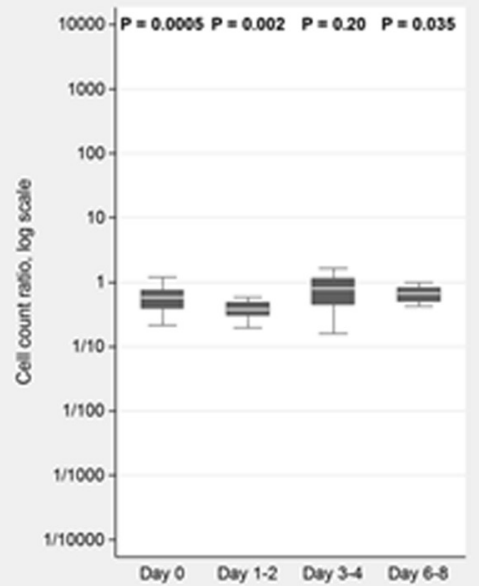

e

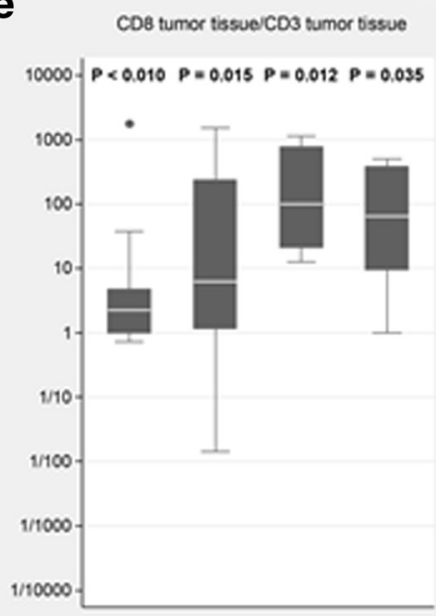

h

CD163 oumor tissue/CD 163 granulasion tissue

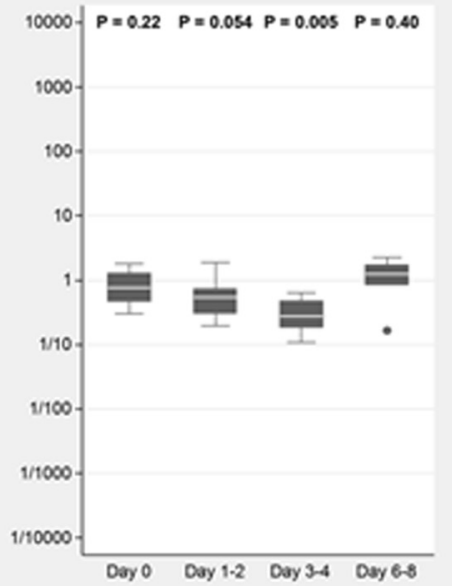

C

COB tumor tissue/CO\& granulaton tissue

$10000-P<0.001 P=0.002 P=0.005 P=0.025$

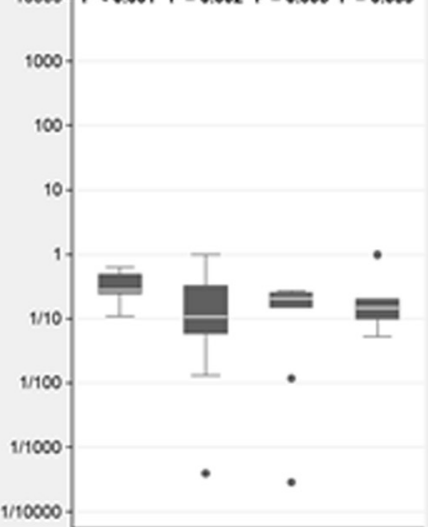

f

$\mathrm{CO} 3$ tumor tissue/ $\mathrm{CO} 2$ tumor bissue

10000 f $p=0.070 \quad P=0.006 \quad P=0.16 \quad p=1.0$

1000

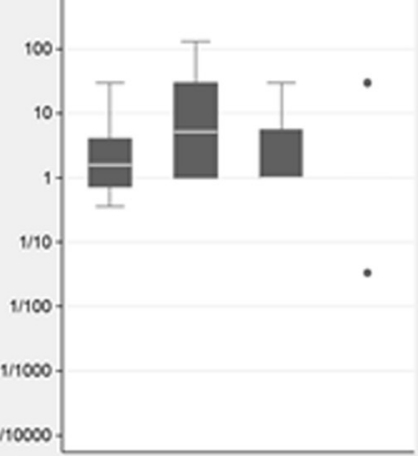

i

CO68 tumor tissuelCO163 tumor vissue

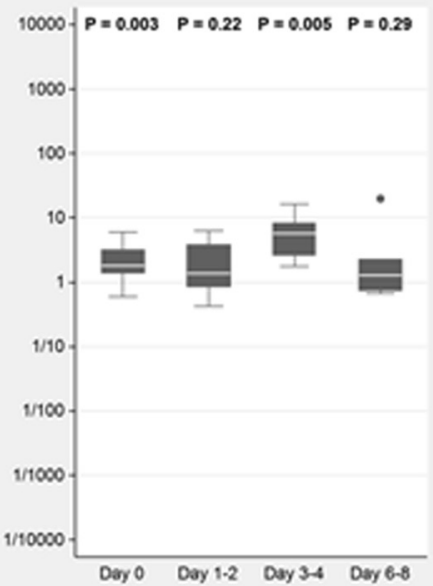

Fig. 2 (See legend on next page.) 
(See figure on previous page.)

Fig. 2 Antigen expression over time. Number of positive cells for the immune cell markers expressed as ratios of expression in tumor cell areas/ granulation area between the tumor cell areas (granulation tissue) over time (box plots, stratified by time interval) in tumors treated with RIT $(\mathbf{a}-\mathbf{c} ; \mathbf{g}-\mathbf{h})$. Number of positive cells for various immune cell marker ratios within the tumor cell areas over time in tumors treated with RIT (d-f; i). A ratio of 1.0 indicates no difference. No box is shown for day 6-8 in F as only two data points were available

was evaluated using multiple linear regression, and the estimated time trends were essentially the same as without adjustment for tumor volume (data not shown). The macrophage markers were only expressed as fragments and had no vital cell association in necrotic areas and necrotic areas were not included in the following analysis.

Both macrophage markers tended to have more positive cells in the granulation tissue (both surrounding and between vital tumor cell areas) than in the vital tumor cell areas (Fig. $2 \mathrm{~g}-\mathrm{h}$ and Table 2). There were a higher number of positive cells for CD68 than CD163 both in untreated tumors and treated tumors.

\section{Discussion}

We have demonstrated that the model used in this study has a higher number of positive cells of immune cell markers augmenting immune rejection of tumor cells than immune tolerance of tumor cells, i.e. a higher number of positive cells for CD8 $\alpha$ than CD2 and CD3 and a higher number of positive cells for CD68 than CD163. The infiltrating immune cells seem to be present to a higher extent in untreated tumors than in tumors treated with RIT. The histological features of untreated tumors and tumors from animals treated with RIT have been described previously, showing that the fraction of granulation tissue increased in tumors treated with RIT (maximum at 4 days p.i.), and that the granulation tissue matured into fibrous tissue which increased throughout the study period [28].

All the immune cell markers were found to have a higher number of positive cells in the granulation tissue than within the vital tumor cell areas. $\mathrm{CD} 8 \alpha$ (antitumor immune cells) decreased less in tumors treated with RIT than the other T-cell markers (CD2 and CD3). The macrophage markers evaluated (CD68 and CD163) decreased less in tumors treated with RIT than the T-cell markers. There was a trend towards a higher number of positive cells for CD68 than CD163 (pro-tumor macrophages) in tumors both before and after the administration of ${ }^{177} \mathrm{Lu}$-BR96.

The observation that the immune cell marker positive cells tended to decrease within the tumors treated with RIT could be explained by the continuous decay of ${ }^{177} \mathrm{Lu}$ in the tumor. Lymphocytes are radiosensitive to low doses of radiation [29-31], while macrophages, natural killer (NK) cells, and dendritic cells (DC) are more resistant to irradiation [29,30]. This could explain why the decrease in CD3 (T-cells) and CD2 (T-cells, B-cells,

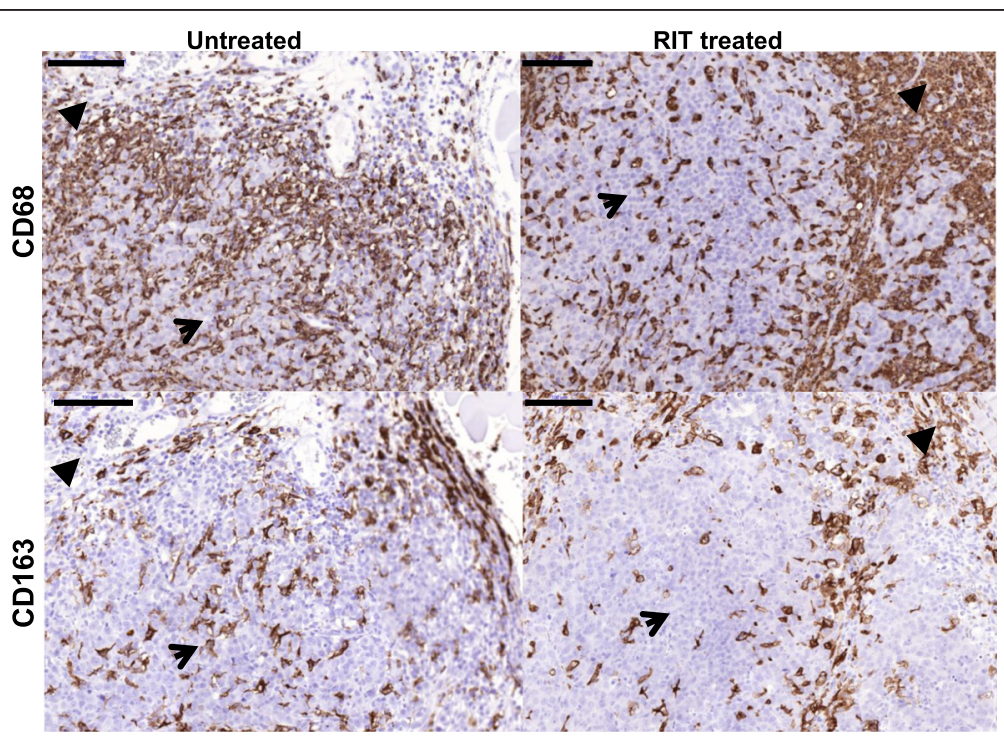

Fig. 3 Images of immunohistochemical sections after staining of macrophage markers. CD68 (macrophages, neutrophils, DC, myeloid progenitors, e.g., myeloid suppressor cell) and CD163 (M2, macrophages of pro-tumor type [26, 27]) in sequential sections of paraffin-embedded tumors. The brown staining illustrates the immune cell markers and the blue staining illustrates the cell nuclei. All images show both granulation tissue (filled arrowhead) and tumor cell area (arrowhead). left: untreated tumors, right: tumor 3 days after administration of radioimmunoconjugate. Note the higher number of positive cells for CD68 during this interval than that of CD163. Scale bars: $100 \mu \mathrm{m}$ 
NK cells) was more pronounced than that of $C D 8 \alpha$ (cytotoxic T-cells, NK cells, subset of DC), CD68 (macrophages, neutrophils, DC, myeloid progenitors), and CD163 (pro-tumor macrophages, M2).

One advantage of immunohistochemical staining is that it provides information on the localization of the antigens within the structures of the tumor. Others have shown that the localization of immune cell markers is an important predictor of clinical outcome [7, 8, 11, 12, 26, 32-34]. Deschoolmeester et al. showed that a high infiltrating CD3- and CD8-positive cells in cancer cell nests was correlated to improved overall survival in colorectal cancer [8]. Pagès et al. suggested an immunological score based on the quantification of $\mathrm{CD} 3, \mathrm{CD} 45 \mathrm{RO}$, and $\mathrm{CD} 8$ in the core of the tumor and in the invasive margin within the tumor samples. This score was found to be a better predictor of patient survival than the histopathological methods currently used to stage colorectal cancer $[11,12,33]$.

The results of immunohistochemical examinations cannot be related directly to cell type, mainly due to the expression of immune cell markers on more than one cell type. The immune cell markers used in the present study and their expression on various immune cells are summarized in Table 1 . In the present study, T-cells stained positive for both anti-CD3 and anti-CD2, but CD2 is also expressed by NK and B-cells. CD8 $\alpha$ is expressed by cytotoxic T-cells (which also express CD2 and CD3) and NK cells, and a subset of DC. The CD68 antigen is expressed by all macrophages, neutrophils, basophils, DC, and myeloid progenitor cells (e.g., myeloidderived suppressor cell), while CD163 is expressed by M2 (pro-tumor macrophages) [26, 27].

The therapeutic effect of external irradiation on distant non-irradiated tumor cells (the abscopal effect) has been shown to be at least partly due to the induction of the immune response [29, 31, 35-41]. However, both the radiation dose and the delivery schedule seem to be important for the induction of the abscopal effect $[31,35,37,38,40-43]$. It has been demonstrated that these factors can affect the infiltration of CD8 $\alpha$-positive T-cells in tumors $[29,35,38,40,43]$ and affect the type of the macrophage response (pro-tumor, M2, or anti-tumor, M1) $[35,40,42,44]$. In a recent study, we demonstrated that early depletion of CD8-positive cells in our rat model treated with RIT seemed not to affect the rejection of the inoculated tumor but increased the number of animals developing metastases [45]. This finding provides evidence that the presence of CD8-positive cells is important in preventing or delaying the development of metastases in this model.

It is of therapeutic interest to evaluate the mechanisms activating the immune system, and to the best of our knowledge this is the first study to evaluate the infiltration of immune cells in tumors after the administration of a radioimmunoconjugate. In future studies, we intend to investigate the effects of combining RIT and immunotherapy in our immunocompetent syngeneic rat tumor model.

\section{Conclusions}

Analysis of the number and localization of immune cell markers within a local tumor at the time of treatment and during rejection after administration of ${ }^{177} \mathrm{Lu}-\mathrm{BR} 96$ antibodies revealed that all the immune cell markers had a higher number of positive cells in adjacent granulation tissue than in tumor cell areas, and that positive cells for T-cell markers decreased more than positive cells for macrophage markers in tumors treated with RIT. We have thus demonstrated that RIT in this model induce both a shift in the balance to a higher number of cells expressing immune cell markers related to immune rejection than markers related to immune tolerance of tumor cells and also a decrease in cells expressing immune cell markers during RIT compared with untreated tumors.

\section{Abbreviations}

BN: Brown Norway; CR: complete response; DC: dendritic cell; DOTA: 1,4,7,10-tetraazacyclododecane-1,4,7,10-tetraacetic acid; EDTA: ethylenediaminetetraacetic acid; HPLC: high-performance liquid chromatography; HSA: Human serum albumin; ITLC: instant thin-layer chromatography; NK cells: natural killer cells; PBS: phosphate-buffered saline; PI: postinjection; RIT: radioimmunotherapy.

\section{Competing interests}

The authors declare that they have no competing interests.

\section{Authors' contributions}

EE participated in study design and performing the in vivo studies, optimizing and performing the immunohistochemistry, and wrote the manuscript. SEE participated in planning and performing the in vivo studies and drafting the manuscript. OL evaluated the immunohistochemical slides. POB performed the statistical calculations and helped drafting the manuscript. TGO performed the radiolabelling. RN and JT participated in the study design and drafting the manuscript. All authors read and approved the final manuscript.

\section{Acknowledgements}

We would like to thank Dr. Peter Senter (Seattle Genetics Inc.) for kindly providing the monoclonal antibody BR96 and Anna Ebbesson for her expertise in the art of immunohistochemical staining. This research was supported by grants from the Swedish Cancer Society, Mrs. Berta Kamprad's Foundation, Gunnar Nilsson's Foundation, Governmental Funding of Clinical Research within the National Health Service, King Gustaf V's Jubilee Foundation, The Lund University Medical Faculty Foundation, and The Lund University Hospital Fund.

\section{Author details}

${ }^{1}$ Department of Clinical Sciences Lund, Division of Oncology and Pathology, Lund University, Barngatan 2B, SE-221 85 Lund, Sweden. ${ }^{2}$ Department of Laboratory Medicine, Clinical Pathology, Skane University Hospital, Lund, Sweden. ${ }^{3}$ Department of Medical Radiation Physics, Lund University, Lund, Sweden. ${ }^{4}$ Department of Oncology, Skane University Hospital, Lund, Sweden.

Received: 24 June 2015 Accepted: 28 August 2015

Published online: 15 September 2015

\section{References}

1. Sporn MB. The war on cancer. Lancet. 1996;347:1377-81. 
2. Swann JB, Smyth MJ. Immune surveillance of tumors. J Clin Invest. 2007;117:1137-46.

3. Ostrand-Rosenberg S. Immune surveillance: a balance between protumor and antitumor immunity. Curr Opin Genet Dev. 2008;18:11-8.

4. Mlecnik B, Bindea G, Pages F, Galon J. Tumor immunosurveillance in human cancers. Cancer Metastasis Rev. 2011;30:5-12.

5. Fridman WH, Mlecnik B, Bindea G, Pages F, Galon J. Immunosurveillance in human non-viral cancers. Curr Opin Immunol. 2011;23:272-8.

6. Schreiber RD, Old LJ, Smyth MJ. Cancer immunoediting: integrating immunity's roles in cancer suppression and promotion. Science. 2011;331:1565-70.

7. Fridman WH, Galon J, Pages F, Tartour E, Sautes-Fridman C, Kroemer G Prognostic and predictive impact of intra- and peritumoral immune infiltrates. Cancer Res. 2011;71:5601-5.

8. Deschoolmeester V, Baay M, Van Marck E, Weyler J, Vermeulen P, Lardon F, et al. Tumor infiltrating lymphocytes: an intriguing player in the survival of colorectal cancer patients. BMC Immunol. 2010;11:19.

9. Taube JM. Emerging immunologic biomarkers: setting the (TNM-immune) stage. Clin Cancer Res. 2014;20:2023-5.

10. Yasuda K, Nirei T, Sunami E, Nagawa H, Kitayama J. Density of CD4(+) and CD8(+) T lymphocytes in biopsy samples can be a predictor of pathological response to chemoradiotherapy (CRT) for rectal cancer. Radiat Oncol. 2011;6:49.

11. Pages F, Kirilovsky A, Mlecnik B, Asslaber M, Tosolini M, Bindea G, et al. In situ cytotoxic and memory T cells predict outcome in patients with early-stage colorectal cancer. J Clin Oncol. 2009;27:5944-51.

12. Galon J, Mlecnik B, Bindea G, Angell HK, Berger A, Lagorce C, et al. Towards the introduction of the 'Immunoscore' in the classification of malignant tumours. J Pathol. 2014;232:199-209.

13. Ascierto PA, Capone M, Urba WJ, Bifulco CB, Botti G, Lugli A, et al. The additional facet of immunoscore: immunoprofiling as a possible predictive tool for cancer treatment. J Transl Med. 2013;11:54

14. Rothschild SI, Thommen DS, Moersig W, Muller P, Zippelius A. Cancer immunology-development of novel anti-cancer therapies. Swiss Med Wkly. 2015;145:w14066

15. Pardoll DM. The blockade of immune checkpoints in cancer immunotherapy. Nat Rev Cancer. 2012;12:252-64.

16. Hodi FS, O'Day SJ, McDermott DF, Weber RW, Sosman JA, Haanen JB, et al. Improved survival with ipilimumab in patients with metastatic melanoma. N Engl J Med. 2010;363:711-23.

17. Eriksson SE, Ohlsson T, Nilsson R, Tennvall J. Treatment with unlabeled mAb BR96 after radioimmunotherapy with ${ }^{177}$ Lu-DOTA-BR96 in a syngeneic rat colon carcinoma model. Cancer Biother Radiopharm. 2012;27:175-82

18. Brodin NT, Jansson B, Hedlund G, Sjogren HO. Use of a monoclonal rat anti-mouse Ig light chain (RAMOL-1) antibody reduces background binding in immunohistochemical and fluorescent antibody analysis. J histochemistry Cytochemistry: Off J Histochemistry Soc. 1989;37:1013-24.

19. Deschavanne PJ, Fertil B. A review of human cell radiosensitivity in vitro. Int J Radiat Oncol Biol Phys. 1996;34:251-66.

20. Sjogren $\mathrm{HO}$, Isaksson M, Willner D, Hellstrom I, Hellstrom KE, Trail PA. Antitumor activity of carcinoma-reactive BR96-doxorubicin conjugate against human carcinomas in athymic mice and rats and syngeneic rat carcinomas in immunocompetent rats. Cancer Res. 1997;57:4530-6.

21. Hellstrom I, Garrigues HJ, Garrigues U, Hellstrom KE. Highly tumor-reactive, internalizing, mouse monoclonal antibodies to Le(y)-related cell surface antigens. Cancer Res. 1990;50:2183-90.

22. Badn W, Kalliomaki S, Widegren B, Sjogren HO. Low-dose combretastatin A4 phosphate enhances the immune response of tumor hosts to experimental colon carcinoma. Clin Cancer Res. 2006;12:4714-9.

23. Eriksson SE, Ohlsson T, Nilsson R, Tennvall J. Repeated radioimmunotherapy with ${ }^{177}$ Lu-DOTA-BR96 in a syngeneic rat colon carcinoma model. Cancer Biother Radiopharm. 2012;27:134-40.

24. Forrer $F$, Chen J, Fani M, Powell $P$, Lohri A, Muller-Brand J, et al. In vitro characterization of (177)Lu-radiolabelled chimeric anti-CD20 monoclonal antibody and a preliminary dosimetry study. Eur J Nucl Med Mol Imaging. 2009;36:1443-52

25. Martensson L, Nilsson R, Ohlsson T, Sjogren HO, Strand SE, Tennvall J. High-dose radioimmunotherapy combined with extracorporeal depletion in a syngeneic rat tumor model: evaluation of toxicity, therapeutic effect, and tumor model. Cancer. 2010;116:1043-52.
26. Gutkin DW, Shurin MR. Clinical evaluation of systemic and local immune responses in cancer: time for integration. Cancer Immunology Immunotherapy : CII. 2014;63:45-57.

27. Engstrom A, Erlandsson A, Delbro D, Wijkander J. Conditioned media from macrophages of M1, but not M2 phenotype, inhibit the proliferation of the colon cancer cell lines HT-29 and CACO-2. Int J Oncol. 2014;44:385-92.

28. Elgstrom E, Ljungberg O, Eriksson SE, Orbom A, Strand SE, Ohlsson TG, et al. Change in cell death markers during Lu-mAb radioimmunotherapy-induced rejection of syngeneic rat colon carcinoma. Cancer Biother Radiopharm. 2014. doi:10.1089/cbr.2013.1576.

29. Frey B, Rubner $Y$, Kulzer L, Werthmoller N, Weiss EM, Fietkau R, et al. Antitumor immune responses induced by ionizing irradiation and further immune stimulation. Cancer Immunology Immunotherapy : CII. 2014;63:29-36.

30. Finkelstein SE, Fishman M. Clinical opportunities in combining immunotherapy with radiation therapy. Front Oncology. 2012;2:169.

31. Siva S, Macmanus MP, Martin RF, Martin OA. Abscopal effects of radiation therapy: a clinical review for the radiobiologist. Cancer Lett. 2013. doi:10.1016/j.canlet.2013.09.018.

32. Rahir G, Moser M. Tumor microenvironment and lymphocyte infiltration. Cancer Immunology Immunotherapy: CII. 2012;61:751-9.

33. Galon J, Costes A, Sanchez-Cabo F, Kirilovsky A, Mlecnik B, Lagorce-Pages C, et al. Type, density, and location of immune cells within human colorectal tumors predict clinical outcome. Science. 2006;313:1960-4.

34. Fridman WH, Pages F, Sautes-Fridman C, Galon J. The immune contexture in human tumours: impact on clinical outcome. Nat Rev Cancer. 2012;12:298-306.

35. Rodel F, Frey B, Multhoff G, Gaipl U. Contribution of the immune system to bystander and non-targeted effects of ionizing radiation. Cancer Lett. 2015:356:105-13.

36. Park $B$, Yee $C$, Lee $K M$. The effect of radiation on the immune response to cancers. Int J Mol Sci. 2014;15:927-43.

37. Tang C, Wang X, Soh H, Seyedin S, Cortez MA, Krishnan S, et al. Combining radiation and immunotherapy: a new systemic therapy for solid tumors? Cancer Immunology Res. 2014;2:831-8.

38. Crister Ceberg BRRP. Co-operative radio-immune-stimulating cancer therapy. Trends Cancer Res. 2013;9:87-108

39. Golden EB, Formenti SC. Is tumor (R)ejection by the immune system the "5th R" of radiobiology? Oncoimmunology. 2014;3, e28133.

40. Lumniczky K, Safrany G. The impact of radiation therapy on the antitumor immunity: local effects and systemic consequences. Cancer Lett. 2015;356:114-25.

41. Durante M, Reppingen N, Held KD. Immunologically augmented cancer treatment using modern radiotherapy. Trends Mol Med. 2013;19:565-82.

42. Hellevik T, Martinez-Zubiaurre I. Radiotherapy and the tumor stroma: the importance of dose and fractionation. Front Oncology. 2014;4:1.

43. Ahmed MM, Hodge JW, Guha C, Bernhard EJ, Vikram B, Coleman CN. Harnessing the potential of radiation-induced immune modulation for cancer therapy. Cancer Immunology Res. 2013;1:280-4.

44. Klug F, Prakash H, Huber PE, Seibel T, Bender N, Halama N, et al. Low-dose irradiation programs macrophage differentiation to an iNOS(+)/M1 phenotype that orchestrates effective T cell immunotherapy. Cancer cell. 2013;24:589-602.

45. Elgstrom E, Eriksson SE, Ohlsson TG, Nilsson R, Tennvall J. Role of CD8-positive cells in radioimmunotherapy utilizing (177)Lu-mAbs in an immunocompetent rat colon carcinoma model. EJNMMI Res. 2015:5:3.

\section{Submit your manuscript to a SpringerOpen ${ }^{\circ}$ journal and benefit from:}

- Convenient online submission

Rigorous peer review

- Immediate publication on acceptance

- Open access: articles freely available online

- High visibility within the field

- Retaining the copyright to your article

Submit your next manuscript at $>$ springeropen.com 